\title{
Evaluation of Historic Buildings Based on Structural Equation Models
}

\author{
Qiaohui Tong ${ }^{1}$, Tianzhen $\mathrm{Liu}^{2}$, Hengqing Tong ${ }^{2}$, and Zhuoling $\mathrm{Ou}^{2}$ \\ ${ }^{1}$ School of Urban Design, Wuhan University, \\ Wuhan, Hubei, 430070, P.R. China \\ qhtong@whu .edu.cn \\ 2 Department of Mathematics, Wuhan University of Technology, \\ Wuhan, Hubei, 430070, P.R. China \\ tonghq2005@mail. whut.edu.cn
}

\begin{abstract}
This paper proposes a quantitative method for historic buildings evaluation, which is the essential step before conservation decisions. We introduce Structural Equation Models (SEM) in the evaluation of historic buildings making evaluation more objective. We select certain independent variables and dependent variables, including the first degree and the second degree indexes and relationships among them, and put forward an applicable index system which could be spread in all historic sites 1
\end{abstract}

Keywords: Structural equation models, Evaluation, Historic buildings.

\section{Introduction}

Historic buildings are the most important evidence of the past life style and cannot be regenerated for human being in society. Generally speaking historic buildings include relic, old buildings and outstanding modern architecture in the historical city. Preservation of historic buildings is always the emphasis of research of city planning and architecture, and is also the necessary work of governmental decision-making. For protection of historic buildings, we should classify the grade of buildings and separate different kinds of the buildings. Therefore, evaluation of historic buildings should be put forward and make corresponding settlement for different grade historic buildings.

Compared with other professional field, architecture field lacks for qualitative and quantitative analysis. We need to introduce mathematic method to architecture field, especially to the work of historic buildings evaluation.

There always are index systems in many work of historic buildings evaluation, and these indexes need to be summarized. Traditionally the summarizing coefficients are designated aforehand. However, in this paper we introduce a method in which the summarizing coefficients are calculated by samples, so it is more objective, and could offer more deep analysis for the index systems.

\footnotetext{
1 The project was supported by the National Natural Science Foundation of China(2006, 30570611).
} 


\section{SEM for Evaluation of Historic Buildings}

Structural equation modeling (also SEM) has become a very popular dataanalytic technique. It is widely applied in Psychology and Sociology as well as other fields, especially in Customer Satisfaction Index (CSI) model which is required by a series of ISO9000 criterions. The researches of SEM are very plentiful and incessancy (C. Fornell, et al., 1996; S. Auh and M.D. Johnson, 2005).

There are two systems of equations in a SEM. One is a structural system of equations among structural variables, and another is an observation system of equations between structural variables and observed variables. Now we build a SEM for evaluation of historic buildings. The model includes 5 structure variables and 18 observed variables. The variables are in the Table 1 as follows. Notice that the numbers of observed variables corresponding each structure variable are $4,4,4,2,4$.

Table 1. Index of Variables

\begin{tabular}{|c|c|c|c|c|c|}
\hline \multicolumn{2}{|c|}{$\begin{array}{l}\text { Structure } \\
\text { variables }\end{array}$} & \multicolumn{4}{|c|}{ Observed variables } \\
\hline$\xi_{1}$ & Historic value & $\begin{array}{l}\text { Time of the } \\
\text { building }\end{array}$ & $\begin{array}{l}\text { Degree of the } \\
\text { integrity }\end{array}$ & $\begin{array}{l}\text { Related fa- } \\
\text { mous people } \\
\text { and event }\end{array}$ & \begin{tabular}{|l} 
Degree of re- \\
flection of the \\
local cultural \\
circumstance \\
\end{tabular} \\
\hline$\eta_{1}$ & scientific value & $\begin{array}{ll}\text { Function of } \\
\text { building in } \\
\text { city planning }\end{array}$ & $\begin{array}{l}\text { Value of tech- } \\
\text { nique }\end{array}$ & Scientific use & $\begin{array}{l}\text { Level of the } \\
\text { construction }\end{array}$ \\
\hline$\eta_{2}$ & artful value & $\begin{array}{|lr|}\text { Detail } & \text { and } \\
\text { decoration } & \text { of } \\
\text { the art } & \\
\end{array}$ & $\begin{array}{l}\text { Value of the } \\
\text { landscape near } \\
\text { the building }\end{array}$ & $\begin{array}{l}\text { Façade of the } \\
\text { building }\end{array}$ & $\begin{array}{ll}\text { Interior } & \text { deco- } \\
\text { ration } & \\
\end{array}$ \\
\hline$\eta_{3}$ & useful value & $\begin{array}{l}\text { Quality of the } \\
\text { building }\end{array}$ & $\begin{array}{l}\text { Whether can } \\
\text { be continually } \\
\text { used }\end{array}$ & & \\
\hline$\eta_{4}$ & $\begin{array}{l}\text { protective } \\
\text { value }\end{array}$ & $\begin{array}{l}\text { Reality of pro- } \\
\text { tection }\end{array}$ & $\begin{array}{l}\text { Memorize of } \\
\text { being main- } \\
\text { tained }\end{array}$ & $\begin{array}{l}\text { Value of the } \\
\text { landmark }\end{array}$ & $\begin{array}{ll}\text { Meaning of } \\
\text { protection of } \\
\text { the building }\end{array}$ \\
\hline
\end{tabular}

Among the structure variables there are some path relationships or causalities. These causalities among the structure variables can be expressed as equations as follows.

$$
\left(\begin{array}{l}
\eta_{1} \\
\eta_{2} \\
\eta_{3} \\
\eta_{4}
\end{array}\right)=\left(\begin{array}{lllll}
0 & 0 & 0 & 0 & 0 \\
\beta_{21} & 0 & 0 & 0 & 0 \\
\beta_{31} & \beta_{32} & 0 & 0 & 0 \\
\beta_{41} & \beta_{42} & \beta_{43} & 0 & 0
\end{array}\right)\left(\begin{array}{l}
\eta_{1} \\
\eta_{2} \\
\eta_{3} \\
\eta_{4}
\end{array}\right)+\left(\begin{array}{c}
\gamma_{11} \\
\gamma_{21} \\
\gamma_{31} \\
\gamma_{41}
\end{array}\right) \xi_{1}+\left(\begin{array}{c}
\varepsilon_{\eta 1} \\
\varepsilon_{\eta 2} \\
\varepsilon_{\eta 3} \\
\varepsilon_{\eta 4}
\end{array}\right)
$$

where $\eta_{1} \sim \eta_{4}, \xi_{1}$ are structural variables, $\beta_{i j}$ is the path coefficient from dependent variable $\eta_{j}$ to $\eta_{i}$, and $\gamma_{i j}$ is the path coefficient from independent variable $\xi_{j}$ to dependent variable $\eta_{i}$. 
In general, suppose that $\eta_{1} \sim \eta_{m}$ are $m$ dependent variables, arranging them as a vector $\eta$ by column as (11); and $\xi_{1} \sim \xi_{k}$ are $k$ independent variables, arranging them as a vector $\xi$ by column also. The $m \times m$ square matrix $B$ is the coefficient matrix of $\eta$, the $m \times k$ matrix $\Gamma$ is the coefficient matrix of $\xi, \varepsilon_{\eta}$ is the residual vector, then SEM (1) may be extended as:

$$
\eta=B \eta+\Gamma \xi+\varepsilon_{\eta}
$$

The structural variables are implicit and cannot be observed directly. Each structural variable is corresponding with many observed variables.

Suppose that there are $M$ observed variables and each one has $N$ observed values, then we will get a $N \times M$ matrix. The relationships between the structural variables and the observed variables can also be expressed in equations by two ways of path causality. Let $x_{t j}, j=1, \cdots, S(t)$ be the observed variables corresponding to $\xi_{t}, t=1, \cdots, k$, and $y_{i j}, j=1, \cdots, L(i)$ be the observed variables corresponding to $\eta_{i}, i=1, \cdots, m$, then the observation systems of equations from observed variables to structural variables are:

$$
\begin{gathered}
\xi_{t}=\sum_{j=1}^{S(t)} \psi_{t j} x_{t j}+\varepsilon_{\xi t} \quad, \quad t=1, \cdots, k \\
\eta_{i}=\sum_{j=1}^{L(i)} \omega_{i j} y_{i j}+\varepsilon_{\eta i}, i=1, \cdots, m
\end{gathered}
$$

where $\sum_{t=1}^{k} S(t)+\sum_{i=1}^{m} L(i)=M$.

We call (2) (3) (4) a SEM, and sometimes we call it path analysis model.

At present, the path causality in popular PLS algorithm for SEM is from observed variables to structural variables as (3) (4), and the iterative initial value vector for $\psi_{t j}, \omega_{i j}$ is arbitrary. As we all know, the convergence of the PLS has not been proved well, and its convergence rate may be very slow.

\section{The Best Initial Value in PLS Algorithm of SEM}

We find that arbitrary initial value is not necessary and PLS can be calculated by a suitable iterative initial value based on the least square estimation in the observation equations.

For this reason, we can write the observation systems of equations from structural variables to observed variables. It is also a linear system of equations with some random errors.

$$
\left(\begin{array}{l}
x_{t 1} \\
\vdots \\
x_{t S(t)}
\end{array}\right)=\left(\begin{array}{l}
v_{t 1} \\
\vdots \\
v_{t S(t)}
\end{array}\right) \xi_{t}+\left(\begin{array}{l}
\varepsilon_{x t 1} \\
\vdots \\
\varepsilon_{x t S(t)}
\end{array}\right), t=1, \cdots, k
$$




$$
\left(\begin{array}{l}
y_{i 1} \\
\vdots \\
y_{i L(i)}
\end{array}\right)=\left(\begin{array}{l}
\lambda_{i 1} \\
\vdots \\
\lambda_{i L(i)}
\end{array}\right) \eta_{i}+\left(\begin{array}{l}
\varepsilon_{y} i 1 \\
\vdots \\
\varepsilon_{y i L(i)}
\end{array}\right), i=1, \cdots, m
$$

where $v_{t j}$ and $\lambda_{i j}$ are load items.

Carefully analyzing the relationships among the variables in above equations, we find a series of the least square relationships, and obtain the least square solution of the observation systems of equations from structural variables to observed variables. Our algorithm paper has been accepted by international journal "Mathematical and Computer Modelling" and will be published in 2007. Our algorithm program has been received in DASC software developed by us. More details are omitted here.

\section{Conclusion and Discussion}

According a group of evaluation data by the observed variables, we complete the computation using DASC software. The data example including data files, figures, and calculation results are offered completely. They can be downloaded from my website: http://public.whut.edu.cn/slx/english/index.htm. We should prove our method is successful.

Having got the solution of SEM in evaluation of historic buildings, the path relationship among the indexes and the path effective coefficients, we can deeply analyze and discuss the effective relationships among the indexes.

\section{References}

1. M.S.Waterman: Study on the Evaluation of Indigenous Danger of Architecture Production. Operations Research and Management Science, 16 (2001) 16-18

2. Claes Fornell, Michael D. Johnson, Eugene W. Anderson, Jaesung Cha, Barbara Everitt Bryant: The American Customer Satisfaction Index: Nature, Purpose, and Findings. Journal of Marketing, 60 (4) (1996) 7-18

3. Seigyoung Auh., Michael D. Johnson.: Compatibility Effects in Evaluations of Satisfaction and Loyalty. Journal of Economic Psychology, 26 (1) (2005) 35-57

4. Hengqing Tong: Data Analysis and Statistical Computation(DASC). Electronic publication, Science Press of China, (2005).

5. Chuanmei Wang, Hengqing Tong: Best Iterative Initial Values for PLS in a CSI Model. Mathematical and Computer Modelling, to be published in 2007. 